\title{
Does Aristotle Refute the Harmonia Theory of the Soul?
}

\author{
Douglas J. Young \\ Department of Philosophy, Lycoming College, USA \\ Email: young@lycoming.edu
}

Received October 24 ${ }^{\text {th }}$, 2012; revised November 27 $7^{\text {th }}, 2012$; accepted December $10^{\text {th }}, 2012$

\begin{abstract}
In Aristotle's On the Soul he considers and refutes two versions of the harmonia theory of the soul's relation to the body. According to the harmonia theory, the soul is to the body what the tuning of a musical instrument is to its material parts. Though he believes himself to have entirely dismissed the view, he has not. I argue that Aristotle's hylomorphic account is, in fact, an instance of the harmonia theory.
\end{abstract}

Keywords: Aristotle; Soul; Body; Hylomorphism; Harmonia; Tuning; Mind-Body Problem

\section{Introduction}

Aristotle begins On the Soul by surveying his predecessors' views $(1.2$ - 5). He describes one, the harmonia theory, as both popular and persuasive (Ross, 1961: 1.4.407b27-30). According to this view, the soul "is a kind of tuning (harmonia)" of the body's constituent parts (407b30). A lyre's tuning, for example, is the precise arrangement of its wood, pegs, and strings in virtue of which it can be played in a particular mode. According to the harmonia theory, the soul is the "tuning" of the body's constituent parts in virtue of which it is alive. Aristotle goes to great lengths to refute the harmonia view, despite the apparent similarity to his own hylomorphic account of the soul and body. This has long puzzled commentators. It seems that successful arguments against the harmonia view undercut Aristotle's account of the soul as the form of a living body.

In this paper I argue that Aristotle can coherently reject the harmonia theory without undermining his own view. My case turns on recognizing that there are different specifications of the harmonia account. Aristotle considers, and rejects, only two. According to the first, the soul is a "blending or combining of opposites" (407b30-31). According to the second, the soul is the "ratio or combination" of the parts of the body (407b32-33). Aristotle takes these two arguments as decisive against the view, but they aren't. Even if both arguments were sound, he would not have disentangled himself from the harmonia view. Overlooked in this debate, I claim, is that a harmonia can be a composite material object. I argue that Aristotle is committed to the view that the functionally organized, living body is itself a material harmonia.

I'm not alone in noting the similarity between the harmonia view and Aristotle's positive account. In fact, there is a remarkable unity of opinion among Aristotle's commentators, both ancient and modern. Themistius, in his fourth century commentary on On the Soul, says that those arguing that the soul is a harmonia are "none too close, nor yet too far, from the truth” (Todd, 1996: 25.23-24; Heinze, 1899). These sentiments are echoed by modern commentators as well. R. D. Hicks reports that the harmonia theory is "the one which approaches most nearly to his own formula that the soul is a form... of a natural body capable of life” (Hicks, 1907: p. 263; Ross, 1961: p. 195). Jonathan Barnes agrees and goes even further. The best sense he can make of Aristotle's claim that the soul is an "entelecheia (i.e., actuality) of a potentially living body" is to read it as a version of the harmonia theory (Barnes, 1982: pp. 491492; Charlton, 1985: p. 131). Though commentators have recognized this similarity, they resisted a materialist understanding of the harmonia view.

Aristotle considers the harmonia view, in part, because it seems to avoid a mistake he finds in Plato and the Pythagoreans. Dualist accounts of the Platonic and Pythagorean sort fail to adequately explain why one soul is "attached" to one body. According to Pythagoras it is possible, Aristotle complains, "for any old soul to be inserted into any old body" (407b21-23). Aristotle thinks such metempsychosis is as absurd as the transmigration of carpentry into flutes. The harmonia view avoids any such absurdity; one soul is ontologically dependent on one body's constituent parts just as an individual lyre's tuning is dependent on its wood, pegs, and strings. Aristotle's stated aim in the opening of On the Soul is to adopt what his predecessors got right and to avoid what they got wrong (1.2.403b23-25). As it turns out, the harmonia theorist gets quite a lot right and perhaps, more than Aristotle realized.

\section{Understanding the Alternatives}

After noting the provenance and the popularity of the harmonia theory, he explains how it is commonly understood: "People say that the soul is some sort of harmonia; for, they say, a harmonia is a blending and combination (krasin kai sunthesin) of contraries, and the body results from a combination of contraries" (1.4.407b30-32). Aristotle clarifies the popular version, suggesting that a harmonia should be understood in one of two ways. A harmonia is either:

1) A ratio of the things mixed (logos... tôn mixthentôn, 407b32-33); or

2) A composite (sunthesis, 407b33).

His strategy for defeating the harmonia theorist appears to be a simple dilemma. A harmonia is either a ratio of the things mixed or a composite. He argues that on either specification, the soul cannot be a harmonia. But because it's not obvious how Aristotle means us to understand these two alternatives, a 
bit more detail is in order.

\section{The First Alternative: A Ratio of the Things Mixed}

According to the first alternative, a harmonia is a ratio of the things mixed. In order to unpack this claim, we need to take a closer look at what he has to say about mixtures. Aristotle's fullest treatment of that topic is found in On Generation and Corruption 1.10 (Joachim, 1970).

There Aristotle imagines a skeptic who argues that mixture is impossible. Consider a case where two ingredients are combined, wine and water say. The skeptic argues that one of three things can happen. First, both the ingredients might continue to exist, unaltered, in the resulting combination. In your glass you have a layer of wine, topped with a layer of water. The ingredients haven't been mixed in that case, because there has been no change (other than spatial) in the ingredients. Second, one or the other of the ingredients might be destroyed. A drop of wine in the sea, Aristotle claims, doesn't result in a very dilute mixture of wine and water. The wine, he claims, is destroyed. It is converted into water, resulting in a sea that is one drop fuller ${ }^{1}$. This is not a case of mixture. Third, both of the ingredients might be destroyed. Again we have a case of destruction, not mixture. So since the ingredients of the combination must either exist unaltered or are destroyed, the skeptic concludes that mixture is impossible.

Aristotle doesn't think that we must, on account of these skeptical worries, be saddled with their conclusion. Mixture is possible. So Aristotle invokes these skeptical suggestions for another purpose- - they are meant to highlight the characteristic features a proper mixture must have. Aristotle claims there are four.

First, the elements from which the mixtures are formed must react with one another altering the properties of each (327b1-2; $328 \mathrm{~b} 23)$. The result of this alteration is that the mixture is something different than a mere juxtaposition of the elements (Heinaman, 1990: p. 89). Stirring together a spoonful of barley and a spoonful of wheat won't leave you with a mixture. The ingredients which go into a mixture must undergo a change of quality.

Second, the elements exist potentially, but not actually, in the mixture (327b24-26). The ingredients which jointly compose the mixture are not destroyed, as the skeptic thought they might be; they are rather demoted to the level of only existing potentially (Fine, 1996: p. 91). This feature of mixtures is problematic and difficult to understand ${ }^{2}$. But let the following suffice as a first approximation of what Aristotle means here. He says that the constituents exist in the mixture and are not destroyed because "their power to act is preserved" (dunamis, 327b31). What gets preserved in the mixture are (some of) the causal powers of the ingredients. Consider bronze mixed with some tin. He explains that when the two metals are mixed, the tin nearly disappears, imparting only its color to the bronze (328b12-13). The causal power of the tin to appear a certain

\footnotetext{
${ }^{1}$ In On Generation and Corruption 1.10.328a2-25 he writes that "if a great quantity (or large bulk) of one of these materials be brought together with a little (or with a small piece) of another, the effect produced is not mixture but the increase of the dominant; for the other material is transformed into the dominant. That is why a drop of wine does not mix with ten-thousand gallons of water; for its form is dissolved and it is changed so as to merge with the total volume of water".

${ }^{2}$ This feature of Aristotle's mereology seems to distance it from contemporary accounts.
}

color is actually preserved in the alloy, but the tin itself exists only potentially.

Third, the alteration that takes place between the ingredients results in something whose smallest parts are all the same and which all have the same character as the whole (328a5-10), something homoeomerous (Joachim, 1904: p. 75). "It must be the case", Aristotle writes, "that if something is mixed, the mixture is homoeomerous just like any part of water is water" (328b10-11). The mutual alteration that takes place between the ingredients results in a mixture that really is something different, a tertium quid, in which the original elements exists merely in potential.

Finally, all the homoeomerous composites Aristotle considers are mixtures of all the four elements - earth, air, fire and water. Again he writes: "All the mixed bodies which exist around the region of the center (i.e., the Earth) are compounds of the simples" (2.8.334b32-34). So all homoeomerous compounds have the same constituents. What distinguishes one from another, blood from bone, for example? ${ }^{3}$ The ratio or proportion of each element in that compound. Bone has proportionally more earth in it than blood does; blood has proportionally more water in it than bone has. Since each of these mixtures are composed of the same four elements, the defining feature of each homoeomerous compound is the ratio according to which those ingredients have been mixed.

Aristotle's first alternative is, I hope, clearer. When he says that a harmonia is the ratio of things mixed, he means that it's the ratio according to which the four elements are combined in the homoeomerous parts of the body.

\section{The Second Alternative: A Composite}

Let us now turn to the second alternative Aristotle presentsthe view that a harmonia is a composite. To unpack what he has in mind here, we'll need to look into his physics and his biological works.

First for the physics. After his initial presentation of the two alternatives, he suggests that the word "harmonia" has two applications: "the most proper pertains to magnitudes which have motion and position, where it (i.e., the harmonia) is a composite of them" (On the Soul: 1.4.408a6-8). This alternative seems to express a materialist thesis - a harmonia is something composed of material parts. To show that this is the case we need to determine what "magnitudes which have motion and position" are.

A magnitude is a particular quantity. A magnitude with a position, then, is a particular quantity located in some place. In Physics 4.1 - 5 Aristotle investigates what it means for something to have a place or to be in a place. He explains that place "has three dimensions - length, breadth, and depth - the dimensions by which all bodies are bounded" (Ross, 1960: 4.1.209a5-6). Since something that has a place is bounded by three dimensions and something that has a place has a position, something that has a position is bounded by three dimensions. A magnitude which has a position, therefore, is a spatially extended quantity of stuff.

But such a quantity is also capable of motion. Motion in its most general and proper sense Aristotle tells us, is a change of place. In order for something to move, that thing must first be

\footnotetext{
${ }^{3}$ Aristotle thinks blood, bone and sinew are examples of such homoeomerous compounds. See, for example, Generation and Corruption: 1.1.314a20; Meteorology: 4.12.389b23-29 and Parts of Animals: 1.1.640b20.
} 
in one place and then in another. Since motion is a change of place, a fortiori that thing must be located in a place. Only spatially extended objects, then, are capable of motion ${ }^{4}$. So we can conclude that a magnitude which has motion and position is a quantity of stuff that is extended in space. From this we can conclude that a composite of such magnitudes is a whole of spatially extended, i.e., material, parts ${ }^{5}$.

Now for the biology. In two of his biological works, Parts of Animals 2.1 (646a12-24) and in Generation of Animals 1.1 (715a8-15), Aristotle distinguishes three types of composition (sunthesis). He arranges these three types of composition hierarchically in order of increasing complexity (cf. Bogen, 1996: p. 183). At the highest level there are objects like living animals and at the lowest level there are the four elements from which all other material objects are composed.

At the lowest level on the hierarchy we find the composition that occurs between the four elements - earth, air, fire and water (Parts of Animals: 2.1.646a12-13). When these elements have been mixed the result, as we've already seen, is a homoeomerous composite whose smallest parts have the same character as the whole.

At the next level up on the hierarchy are those parts which result from combining the homoeomerous parts. The non-uniform or anhomoeomerous parts which result are not divisible into smaller parts which have the same character as the whole. Combine some flesh, bone, blood and sinew in the right way and you've got a toe, for example. Unlike water, the smallest parts of which are still water, a toe is not divisible into smaller parts of the same character as the whole. The smallest part of a toe is not a toe. So at the second level of composition, the homoeomerous parts combine to form the anhomoeomerous parts of the body ${ }^{6}$.

At the highest level on the hierarchy are living animals, composed of both homoeomerous and anhomoeomerous parts (Parts of Animals: 2.1.646b11-13). The mixture of elements results in flesh, bone and the other organic homoeomeries. The composition of these parts results in organs, limbs and the other anhomoeomeries. The whole living animal is composed of all the parts at the lower levels.

Under what conditions, one might wonder, are these parts correctly fitted together such that they result in a living animal? What is the criterion of correct arrangement for a living body? To answer this, consider the lyre once more. The wood and strings of the lyre have been arranged correctly when the strings have been properly tightened and the wood adequately opposes this tension. In addition, the strings have been properly tensioned when they have been tuned to a particular musical mode. The parts of a lyre have been harmoniously arranged when the

\footnotetext{
${ }^{4}$ More precisely the argument has to do with the kinds of motion souls and magnitudes can undergo. Every magnitude can be moved in its own right (kath hauto, i.e., directly, On the Heavens: 1.2.268b15-16; Physics: 8.6.258b24-26). The soul can only be moved on account of something else being moved (kath heteron i.e., indirectly, On the Soul: 1.3.405b31-406b25). So the soul cannot be a magnitude. The distinction between direct and indirect motion is an important one, but the distinction doesn't make a difference for the present argument.

5I will use the expression 'material parts' to pick out the same thing as "spatially extended parts". Aristotle himself allows that there is a kind of matter which isn't spatially extended namely, intelligible matter. In Metaphysics: Z.10.1036a9-11, for example, he describes objects of mathematics as compounds of form and intelligible matter. Such objects are neither spatially extended nor perceptible. We can leave to one side this curious and contentious matter, however, since Aristotle's present worry is about magnitudes.

${ }^{6}$ See also History of Animals: 1.486a12-15.
}

lyre is able to be played. The criterion for the correct arrangement of the parts of a lyre consists in "its aptitude for performance” (Barnes, 1982: p. 491). The parts of the lyre are correctly arranged when the lyre can perform its intended function. The parts of the body are correctly arranged when they have been fitted together in such a way that the body can perform its vital functions.

The vital functions of a living human body are things like self-nutrition, perception, locomotion and thought. So if the parts of a human body are correctly arranged, the body will be able to carry out these functions. But now this begins to sound very much like Aristotle's view that the soul is the "first actuality of an organized natural body" (On the Soul: 2.1.412b5). We might say that this organization just is the correct arrangement of the parts of the body. An organized natural body is one composed of parts able to carry out the vital functions of the organism. We've just seen, moreover, that an animal body is composed of homoeomerous and anhomoeomerous parts. So when these parts are structured so as to carry out an animal's vital functions, they are organized correctly. If the criterion for the correct arrangement is the capacity for the parts to carry out the vital functions of a living organism, then it's easy to see why confusion arose between this and the harmonia theory. I'll return to this issue below.

\section{Restating the Alternatives}

Now Aristotle's initial presentation of the harmonia theory can be restated with more clarity. He had suggested that a harmonia is either a ratio of the things mixed together or a composite. We now see that he means a harmonia is either:

1) The ratio or proportion according to which the four elements in the homoeomerous parts of the body have been mixed; or

2) The composite of spatially extended parts yielding either: a) the anhomoeomerous parts of the body or b) the body of an organism capable of carrying out a certain set of vital functions.

But these present two problems for Aristotle. His strategy to defeat the harmonia theorist was first to spell out the two ways the theory could be specified and then to argue that it is not possible for the soul to be a harmonia on either specification. For this strategy to be successful, the alternatives presented need to be exhaustive. I think it is clear, however, that the choice between 1) and 2) does not constitute an exhaustive disjunction. There are ways of being a harmonia which do not meet either description. For example, the tuneful blending of high and low notes constitutes a musical harmonia (Timaeus $80 \mathrm{~b})^{7}$. But even if we were to suppose that 1) and 2) did constitute an exhaustive disjunction; 2') b) appears indistinguishable from Aristotle's positive view about the soul.

\section{Aristotle's Refutation}

Having distinguished the two ways he thinks the harmonia theory can be specified, Aristotle offers no less than four (and perhaps five) arguments meant to defeat it (On the Soul 1.4.407b32-408a18). He deploys a barrage of arguments against the theory and it is not always clear where one argument ends and another begins. What he does say is compressed and some-

\footnotetext{
${ }^{7}$ Aristotle refers to Plato's Timaeus at On the Soul 1.3.406b26 ff., just prior to his attack on the harmonia theory of the soul. So it's fair to assume familiarity with the dialogue.
} 


\section{J. YOUNG}

times cryptic. Although all these arguments merit philosophical consideration, let us consider his strongest and most detailed. It is worth seeing the argument in full:

Further, if we use the word "harmonia" we do so according to two applications: the most proper is about magnitudes that have motion and position, a harmonia is a composite of them whenever they've been so fitted together that they admit nothing of the same kind; and then there is the ratio of the things mixed together-in neither case is it reasonable to apply the term to the soul, and the application according to which the soul is a composite of the parts of the body is exceedingly easy to refute.

For there are many composites of parts and they are variously composed. And so what composite of which parts should one take the mind to be? How is it composed? And what about the faculty of perception or appetite? And it is similarly absurd for the soul to be a ratio of the mixture; for the mixture of elements in flesh is not the same as that in bone. And so it would follow that the body has many souls all over, since all its parts are composed of elements mixed together and the ratio of the mixture is a harmonia that is, a soul (408a5-408a18).

Aristotle's argumentative strategy is clear. A harmonia is either a composite or a ratio. Since the soul can be neither of these, the soul cannot be a harmonia. The argument then begins by explaining the disjunction he faces in the first premise.

Aristotle suggests that the word "harmonia" has two applications. The most proper application of the term is to pick out "magnitudes that have motion and position" $(408 a 6-7)^{8}$. According to this application of the term, a harmonia is an extended, material composite. More specifically, it is a composite of spatially extended parts which could either be the anhomoeomerous parts of the body or the body of an organism capable of carrying out a certain set of vital functions. "Harmonia" is used in its secondary application to pick out the ratio of the things mixed in the body (408a8-9). Understood in this way, a harmonia is the ratio according to which the four elements are mixed in the homoeomerous parts of the body. That is, it's a mathematical property. Aristotle takes these as exhausting the possibilities — and the soul, he claims, can be neither.

\section{The First Horn: The Soul Is a Composite}

On the first horn of the dilemma, Aristotle targets the view that the soul is a harmonia understood as a composite of the parts of the body. He's rather dismissive of it, claiming that the view is "exceedingly easy to refute" (408a10-11). As I've argued, this specification of the harmonia theory expresses a materialist thesis: the soul is composed of material parts put together in a particular arrangement. This materialist thesis can be specified in three ways, given the hierarchical model of composition described above.

1) A harmonia is one of the homoeomerous parts of the body such as flesh and blood. These material composites result from mixing earth, air, fire and water.

\footnotetext{
${ }^{8}$ One might wonder why Aristotle considers this the most proper application of the term. Aristotle explains that we acquire first principles by first perceiving particular things which are "better known to us" to understanding universals which are "better known in themselves". See, for example, Physics: 1.1.184a16-20 and Metaphysics: Z.3.1029b3-12. Since perceptible, material objects are "better known to us" the primary application of "harmonia" belongs to these things. A shift in use from concrete to abstract is described by (Ilievski, 1993) and (Meyer, 1932).

${ }^{9}$ In The Second Alternative: A Composite.
}

2) A harmonia is one of the anhomoeomerous parts of the body such as toes or eyes. These material composites are composed of the homoeomerous parts.

3) A harmonia is the living creature itself. This material composite having both homoeomerous and anhomoeomerous parts.

Despite Aristotle's confidence, it is not clear which specification of the theory (if, in fact, he did have a particular specification in mind) the argument is directed against. All he actually does to refute it is to note that there are many different composites of the body and then ask: Which one is the mind or perception or appetite?

If we lean on his claim that there are many composites of the body and they are composed in a variety of different ways (408a11-12), we might suppose the argument is directed against the first two sorts of composite. His qualms have to do with numbers: there are many composites of the body and they are composed in different ways. There is only one soul ${ }^{10}$. If the soul were a composite- a homoeomerous or anhomoeomerous part of the body - which one would it be? It is absurd to suppose that the soul is any particular composite of the body. He concludes that the soul is not a composite and so not a harmonia on this specification.

But consider how the argument would run if it were directed against the view that the soul is a composite of the third sort, namely, the living body itself. If the soul were such a composite, the parts of the soul would be the parts of the living body. The parts of a living body are its homoeomerous and anhomoeomerous parts. Aristotle describes the parts of the soul quite differently (Sorabji, 1975: p. 43). Faculties like the intellect, perception and appetite are the sorts of parts he ascribes to the soul (2.2.413b11-16).

The parts of the soul, Aristotle argues, could not be identical the parts of the living body. His argument consists of rhetorical questions meant to show the absurdity of assuming otherwise. Which composite, Aristotle asks, might the mind or perception or appetite be? No particular homoeomerous or anhomoeomerous part could properly answer this question. Perception is not identical to flesh or the eyes or the ears. Nor are (all) the parts of the soul composed of the parts of the body. At 408a12 Aristotle asks: How would the mind be composed? The mind, he will later argue explicitly, cannot be composed of material parts (3.4.429a10-429b9) $)^{11}$. Since the parts of the soul cannot be identical to or all composed of the parts of the body, the soul cannot be the living body. And since the living body is a toplevel composite and such a composite is a harmonia, the living body is a harmonia. Putting this all together Aristotle can conclude that the soul cannot be a harmonia.

There is a problem, however. By assuming that the faculties of the soul must be certain material composites in the body he ignores a plausible alternative. It seems that various faculties and functions of the soul might not be any particular composite.

\footnotetext{
${ }^{10}$ This would have to be an implicit, though not unreasonable, assumption on Aristotle's part. He argues against the view that the soul is a ratio using just this principle. See below.

${ }^{11}$ The argument for why the intellect lacks a bodily organ is interesting and controversial. Very briefly the argument runs as (roughly) follows: there isn't anything the intellect cannot understand. If the intellect had a bodily organ or were "mixed" with material elements, then there would be things the intellect couldn't understand. So, the intellect doesn't have a bodily organ and is "unmixed" with the body. For a sympathetic reconstruction of this argument see Aquinas' In Aristotelis Librum De Anima Commentarium: 3.7.679-685.
} 
Rather such functions might ontologically depend on the material composites out of which the body is composed, without being identical to them. There are a wide variety of such dependence relations which might obtain between the faculties and functions of the soul and the material composite- the living body or its anhomoeomerous parts-upon which they depend ${ }^{12}$. In fact, the harmonia theory he's arguing against seems to provide just such a relation. The tuned state of the instrument depends on the material parts of the instrument but isn't identical to those parts. If this is the case, Aristotle simply begs the question against the harmonia theorist: perception and appetite might ontologically depend on material composites, but are not identical to or composed of them ${ }^{13}$.

\section{The Second Horn: The Soul Is a Ratio}

On the second horn of the dilemma, Aristotle argues that the soul is not a ratio of the parts mixed together. The argument is a straightforward reductio ad absurdum. If the soul were a ratio of the parts mixed together, it would be the ratio according to which the homoeomerous parts of the body are composed. We've seen why this is the case above. But the body is composed of a variety of such parts. Flesh, bone, blood and sinew are some of the examples he mentions. Were the soul a ratio of the elements of these parts, there would be as many souls as homoeomerous parts. But it gets worse. According to the hierarchical model of composition, the anhomoeomerous parts are composed of the homoeomerous ones. So not only does the body have more than one soul, but even the anhomoeomerous parts of the body have as many souls as they have parts. Since Aristotle assumes that one cannot attribute more than one soul to an individual (let alone attributing more than one soul to one's toe) he concludes that the soul cannot be a ratio.

\section{The Upshot}

With this, the dilemma is complete. A harmonia is either a composite or a ratio of the things mixed. In either case a harmonia cannot be identical to the soul. There are two problems with this argument, however. First, the argument against the first disjunct isn't sound. Contrary to one of its premises, it is possible for there to be faculties of the soul which ontologically depend on, but are not identical to, the material composites of the living body. Second, the choice between a harmonia as a composite or as a ratio of the things mixed is not exhaustive. There are structures which are not ratios or composites as Aristotle conceives of them. Simply put, Aristotle dismisses the harmonia theory with an offhandedness it is not clear he is entitled to enjoy—not only does the argument he presents contain a false premise, it's also invalid.

\section{The Relation between the Soul \& the Body}

If Aristotle doesn't think the soul is a harmonia, what does

\footnotetext{
${ }^{12}$ Metaphysicians of mind have catalogued a number of ways the mind might depend on, without being identified with, a composite material object. Nonreductive physicalists, for instance, deny that the mental and physical are identical but insist that any mental change requires an underlying material change. See (Caston, 1997) for an excellent discussion of the harmonia theory as a non-reductive physicalist account of the mind-body relation.

${ }^{13}$ As I argue below, on Aristotle's own view the soul in some sense depends on the material body, though it is not identical to it. What's odd is that he doesn't explicitly consider this view in connection with his discussion of the harmonia theory.
}

he think it is? It is well known that he understands the relationship between the soul and the body to be special case of the relationship between form and matter-the soul is the form of the body. I will now try to show that Aristotle is committed to the view that the living body is a harmonia of which the soul is its form.

Let us begin, then, with Aristotle's definition(s) of the soul in On the Soul 2.1. There he presents three definitions, or better, three versions of the definition of the soul (Ackrill, 1973: p. 65). The soul is either:

1) The form of a natural body that is potentially alive;

2) The first actuality of a natural body that has life potentially; or

3) The first actuality of an organized natural body ${ }^{14}$.

To understand what sort of body it is that Aristotle claims the soul is the form of, we'll need to examine what these various expressions mean. What does it mean to say that something is a "natural body that is potentially alive" or a "natural body that has life potentially" or an "organized natural body"? Aristotle intends these expressions to have the same referent. A natural body that is potentially alive is an organized natural body. Since these expressions are equivalent, Aristotle is making three claims about what sort of body the soul is the form of-a body that is natural, potentially alive, and organized.

First, the body is natural. A natural body, quite reasonably, is a body with a nature. In Physics 2.1 Aristotle explains that "the nature is the shape and form of things that have within themselves a principle of motion and rest; the form is not separable except in account” (193b4-5) ${ }^{15}$. What distinguishes a living body from an artifact is that the former has within itself an "internal principle of motion and rest." So a natural body is one which has a form, but a form which is responsible for the motion and rest of the animal it informs.

Second, Aristotle claims that the body is potentially alive. Seemingly paradoxically, it turns out that this does not mean that the body can come to be alive. Rather, it means that the body is an actual, living body with all of the proper vital capacities. He claims: "the sort of body that is potentially alive is not one that has lost its soul, but one which has it" (412b6).

To see what he means, we need to call upon Aristotle's distinction between the levels of potentiality and actuality ${ }^{16}$. Consider the capacity for walking. When a person is actually walking, she is said to be at the level of second actuality with respect to this capacity. A person who is able to walk, but who is not actually walking, is said to be at the level of first actuality with respect to this capacity. Aristotle also calls this second potentiality. An infant who is not yet able to walk is said to be at the level of first potentiality with respect to this capacity.

When Aristotle says that a body is potentially alive, he could either mean that the body is at the level of first or second potentiality with respect to that capacity. A body at the level of first potentiality is a body in name only, according to Aristotle. Just like an axe which no longer has the capacity for chopping wood is an "axe" only in name, so also a body which no longer has

\footnotetext{
${ }^{14}$ Options 1 and 2 are found at 412a20-21; option 3 at 412a20-21.

${ }^{15}$ Although Aristotle here claims that the form, and so the soul, is separable only in account. There is evidence in On the Soul which suggests that part of the soul-the active intellect-might be capable of existing without the body. See, for example, 2.1.413a3-9, 2.2.413b24-28 and 3.5 especially 430a22-25. Although this evidence is not uncontested, Aristotle at least allows the possibility that the active intellect is separable both in account and in space.

${ }^{16}$ On the Soul: 2.1.412b6-413a3; Physics: 3.1.201a10-201b15.
} 
the capacities necessary for living is a "body" in name only (On the Soul 2.1.412b10-413a5). But a body capable of self-nutriation, perception and self-motion is an ensouled body (Barnes, 1975: p. 33). So a body that is "potentially alive" is one which is ensouled-it is at the level of second potentiality with respect to the capacities for living. The soul is the first actuality of that sort of body.

The structure of this sort of body is explained by Aristotle's third claim: the body is organized ${ }^{17}$. A body which is capable of supporting nutrition, perception and motion (and perhaps understanding), is one which has a very particular structure. The parts of the body must be arranged such that the animal is able to perform these various vital functions. Such a functionally organized body is essentially ensouled. A body without a soul is a "body" in name only. As we've seen, the soul is the form of the body-it explains why the body is composed and organized as it is. That it doesn't explain what sort of structure is capable of carrying out the animal's vital functions.

But we do know how the functionally organized body is composed from the hierarchical model of composition presented in the biological works ${ }^{18}$. We've seen that Aristotle describes three levels of composition. Mixtures are the result of combining the four elements. These homoeomoerous parts of the body (e.g., flesh, bone, blood and sinew) combine to form more complex parts like fingers and toes. Put all these parts together in the right way and you've got an animal body; one structured such to carry out the animal's vital functions. The organized living body is the most complex biological composite. And this means that the "organized natural body" just is a material harmonia.

In rejecting the harmonia theory, Aristotle presented two possibilities: a harmonia is either the ratio of the things mixed or a composite. He argues that the soul is neither of these. But given the model of composition in the biological works, he is committed to the view that the functionally organized body is a material harmonia. And so, I suggest that we ought to understand Aristotle's definition as follows: the soul is the form of a material harmonia.

\section{An Objection and Reply}

Some have objected to this line of argument by claiming that Aristotle things the soul is identical to the functionally organized body (Irwin, 1988: p. 285; Whiting, 1992: p. 81). If the soul and the living body are identical, then Aristotle has unwittingly committed himself to the version of the harmonia theory he rejects outright. I will show that the evidence does not show that the soul and functional body are identical, rather they are two constituents parts of a unified whole.

Here is the evidence appealed to which purportedly shows the identity between the soul and the functionally organized body:

[I]t's not necessary to ask if the soul and the body are one, just like its not necessary to ask it the wax and the shape are, nor generally about the matter of each thing and that of which it's the matter (412b6-9).

So in whatever way form and matter are one, the soul and the body will also be one. This view is supported and explained in an important, though murky, passage in Metaphysics H.6 (Ross,

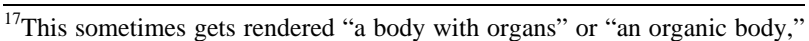
but calling the body organized seems to do just as well.

${ }^{18}$ Parts of Animals: 2.1.646a12-24; Generation of Animals: 1.1.715a8-15.
}

1953). There we find the following:

As we've said, the proximate matter and the form are the same and one-the former potentially, the latter actually so that the search for the cause of the oneness is like the search for their being one. For each thing is one, and the potentiality and the actuality are in a way one... (1045b17-21).

Let me clarify the terminology here. Aristotle distinguishes different types of matter, in part, by differences in their persistence conditions. The persistence conditions for some types of matter are determined according to their level of organization. Some material parts survive the death of the organism ${ }^{19}$. That is, their identity as the sorts of parts they are is not determined by the whole of which they are parts. Aristotle writes: "the clay statue is destroyed into clay, the bronze sphere into bronze and Callias into flesh and bones” (Metaphysics: Z.10.1035a31-33). The flesh and bone into which Callias is destroyed is his "remote" ${ }^{20}$ matter.

Some material parts of an organism, however, cease to exist when they're no longer parts of a functioning whole ${ }^{21}$. Their persistence conditions are bound up with their being functioning parts of a living organism. The "proximate" matter of a living creature persists only so long as it can fulfill its function. A finger or an eye is what it is only while it is part of a functioning whole. For Aristotle, a severed "finger" or the "eye" of a corpse is a finger or an eye in name only. These organic parts are the proximate matter of the living organism.

Aristotle broadens this claim: "We must apply to the whole living body that which applies to the part" (On the Soul: 2.1.412b22-23). From this it seems reasonable to take the whole organic body as the proximate body of the organism. Just as a stone or painted "eye" lacks the capacities characteristic of a real, functioning eye and so is an eye in name only; so also a dead body lacks the capacities characteristic of a functioning organic body. Hence he claims that the organic body is essentially ensouled. Again, "it is not the body that has lost a soul that has the potentiality to live, but the body that has it" (412b25-6). The body that has a soul has the right sort of capacities for living and does not survive the death of the organism. That sort of body serves as the proximate matter of the living organism. The body that lacks a soul lacks the capacities for living and can survive the death of the organism. But the "body" that lacks the soul is just a heap of elements-the remote matter which persists after the death of the organism.

To this point, I've shown the evidence suggesting that the soul and body are one in the same way as the wax and its shape are one. Also, I've shown that the proximate matter-which we should now understand as the functionally organized bodyand the form are "the same and one". But does this mean that the soul and the body are identical?

\section{The Same and One...}

Aristotle occasionally uses the expression "the same and one” to mean identity, as we do in English (White, 1971: p. 178). Uncontroversially, identity is that relation which holds

\footnotetext{
${ }^{19}$ On the Soul 2.1.412b25-26; Metaphysics Z.10.1035a18-19.

${ }^{20}$ The talk of proximity or remoteness has to do with the metaphorical distance the matter is from the target form. This 'distance' is to be accounted for by the difference in degrees of organization-something with a higher degree of complexity in its organization is further from something with a lower degree of complexity.

${ }^{21}$ On the Soul 2.1.412b13-15; 412b20-22; Parts of Animals 1.1.640b35641a6; 1.5.645a35; Metaphysics Z.10.1035b18-27; Z.11.1036b30-32.
} 
between a thing and itself. Aristotle sometimes uses the phrase to pick out this relation. For example when investigating the one-over-many problem in Metaphysics Z.14 he asks whether "the animal in horse is one and the same as the animal in man as you are one and the same as yourself” (1039a33-34). Though here he uses "one and the same" to express identity, he doesn't always do so.

In his philosophical lexicon, Metaphysics D.6, Aristotle out lines no less than ten different ways we might say that some thing(s) are one; and in D.9, he mentions three things one might mean by "the same”. I won't list them all here. Suffice it to say that not every combination of "one" and "the same" expresses the identity relation. I propose that we ought to understand Aristotle's claims about the oneness of form and matter as a claim about composition and not identity. When he says that form and matter are the same and one, he means that form and matter are the metaphysical parts which together compose a single, unified whole.

The first step in understanding the oneness of the soul and proximate body is to look at Aristotle's account of oneness by continuity, one of the senses distinguished in the philosophical lexicon. The word that gets translated as "continuity," "sunechê," is rendered just as well by "held together". There is a sort of unity, Aristotle claims, between some things when they are held together (D.6.1015b36-1016a1). What makes it the case that some things are held together is not just that they are merely in contact, as the parts of a heap might be. Rather, some things are held together just in case they have been worked up into a whole. Some things can be worked up into a whole by craft, other things by nature.

We distinguish, along with Aristotle, between a heap of stuff and a whole of parts. A whole is distinguished from a heap in as much as the parts of the former have been structured in some principled way. The bits of leather in a pile before the cobbler practices her craft are unstructured; but after they've been properly cut and stitched, they've been worked up into a structure-a shoe. The various bits of leather are one, i.e., parts of a whole, because they've been united under a single form by the skill of the cobbler. The form so imposed is the reason why the parts are held together and are not in a heap. Some things achieve such a condition by nature. A plant has within itself the cause of its own continuity. Plants are not put together like shoes. Aristotle vividly describes how the elemental parts of a plant are prevented from flying apart by the soul:

Further, what is it that holds together (to sunechon) the fire and earth when they are moving in opposite directions? For they will be torn apart unless something prevents it; if there is, it will be the soul... (On the Soul: 2.4.416a6-8).

Because plants are not constantly bursting apart into their elemental constituents, we can presume that the soul is the unifying form which holds the parts together. A plant is a whole of parts held together by the soul. Aristotle defines "a whole" as something that "contains its contents in such a way that they are one thing” (Metaphysics: D.26.1023b27-28). A plant contains its contents in just this way. So what we have is the following account of the oneness of the soul and the body: the soul and body are one in virtue of the fact that they jointly compose something (i.e., the living thing) which is one.

\section{But Different}

Though they still count as being “one” by being parts of a whole, form and matter are different. Aristotle clearly ascribes different, and sometimes incompatible, properties to the soul and the body. To list a few, without comment: a form is the same as its essence, but matter is not (Metaphysics: Z.11.1037a34-b7); forms are substances rather than or more than matter is (Z.3.1029a29-30); forms are definable, but matter is not (Z.11. 1036a28; 1037a27-31). Examples of such differences are easy to multiply. By a simple application of Leibniz' Law, forms have at least one property that matter lacks and so the two can't be identical ${ }^{22}$.

Moreover, I wish to argue that for Aristotle "soul" and "body" have different referents. There is not a single subject which might be picked out by "soul" and by "body." Rather "soul" picks out the structure in virtue of which some material parts compose a whole (something which is itself non-material); while "body" picks out the material parts so structured (something material). In this way, soul and body are parts of a whole (albeit parts in different senses) of a single thing-a living organism.

There is good reason to suppose that Aristotle held this view:

The syllable is not just its elements-BA is not the same as $B$ and $A-$ nor is flesh just fire and earth. For on dissolution the flesh and the syllable no longer exist, but the letters exist, and so do the fire and the earth. So the syllable, then, is not only the elements (the vowel and consonant), but something else besides (Z.17.1041b11-19).

He explains later that this something else is not an element, nor is it composed of elements (1041b25-27). Aristotle is clear about this much at least: in the case of a whole of parts, the whole is a unity, composed of elements and "something else" of a different character. This "something else" is not an element or composed of elements, on pain of regress. This "something else" he describes as "the substance of a particular thing" (1041b27-28).

We know from Metaphysics $\mathrm{Z}$ that the substance of a particular thing is its form. The form is the principle in virtue of which something exists as the sort of thing it is and not something else-its structure. The form is the reason why some earth, air, fire and water are a human being and not a chair. For these elements to be unified into a whole, a form needs to be present.

The form is not an element, but a property and, as it turns out, is described as a part of a composite living thing. To appeal again to Aristotle's lexicon, he defines "part" in a number of ways. The relevant one is that a part "is that into which a whole is divided or out of which it is composed, either the form or that which has the form, for example the bronze (this is the matter in which the form is) is a part of the bronze sphere or cube and the angle is a part" (Metaphysics: D.25.1023b19-22). So the form and matter are parts of a single composite. The soul unifies the material parts of the composite, though it is not material or composed of material parts. The form is responsible for the unity of the material parts, a role it couldn't play were it something material.

In sum, Aristotle's claims about the "oneness" of the form and matter or the soul and body are claims about the unity of

\footnotetext{
${ }^{22}$ Aristotle's analysis of form and matter is as contentious as it is obscure. A detailed discussion of this controversial issue is beyond the scope of this paper. I don't suggest that these considerations are decisive. I am offering one way to trace a line of argument which accounts for Aristotle's apparently conflicting accounts of the soul and body. For related discussion of the non-identity of form and matter, soul and body see for example (Wedin 2000), especially chapter 8; (Code and Moravcsik, 1992); and (Shields, 1988).
} 
distinct metaphysical parts into a whole. The form generally or the soul specifically is the principle according to which some material parts are structured. Though this principle is not an element or composed of elements, it is still properly understood as part of a whole-albeit a part of a very different sort than the material parts so structured.

\section{Conclusion}

There are different versions of the harmonia theory. Aristotle considers two very narrow specifications: a harmonia is either a ratio of certain parts of the body or it's a material composite, namely, the living body. Thus he is able to reject both of these without, thereby, undercutting his view that the soul is the form of a living body. The reason for the perplexity of Aristotle's commentators is that it turns out that he's committed to a version of the view he's trying to refute. He rejects versions of the harmonia theory, but in the end the view he accepts is itself a harmonia account. By carefully distinguishing and arguing against the versions of the theory he finds objectionable, Aristotle is able to accept what the harmonia theory gets right namely, that the soul is the structure of the living body.

\section{REFERENCES}

Ackrill, J. L. (1973). Aristotle's definitions of Psuche. Proceedings of the Aristotelian Society, 73, 119-133.

Barnes, J. (1982). The presocratic philosophers. Boston, MA: Routledge.

Barnes, J. (1975). Aristotle's concept of mind. In J. Barnes, M. Schofield, \& R. Sorabji (Eds.), Articles on Aristotle, psychology and aesthetics (pp. 32-41). London: Duckworth.

Bogen, J. (1996). Fire in the belly: Aristotelian elements, organisms, and chemical compounds. In F. A. Lewis, \& R. Bolton (Eds.), Form, matter, and mixture in Aristotle (pp. 183-216). Malden, MA: Blackwell Pub- lishers.

Caston, V. (1997). Epiphenomenalisms, ancient and modern. The Philosophical Review, 106, 309-363. doi:10.2307/2998397

Code, A., \& Moravcsik, J. (1992). Explaining various forms of living. In M. C. Nussbaum, \& A. Rorty (Eds.), Essays on Aristotle's De anima (pp. 129-145). Oxford; New York: Clarendon Press; Oxford
University Press.

Charlton, W. (1985). Aristotle and the Harmonia theory. In A. Gotthelf (Ed.), Aristotle on nature and living things: Philosophical and historical studies (pp. 131-150). Pittsburgh, PA: Mathesis Publications Inc.

Fine, K. (1996). The problem of mixture. In F. A. Lewis, \& R. Bolton (Eds.), Form, matter, and mixture in Aristotle. Malden, MA: Blackwell Publishers.

Heinaman, R. (1990). Aristotle and the mind-body problem. Phronesis, 35, 83-102. doi:10.1163/156852890X00042

Heinze, R. (1899). Themistius: In libros Aristotelis De Anima paraphrasis. Commentaria in Aristotelem Graeca 5.

Hicks, R. D. (1907). Aristotle: De anima; with translation, introduction and notes. Cambridge: University Press.

Ilievski, P. H. (1993). The origin and semantic development of the term harmony. Illinois Classical Studies, 18, 19-29.

Irwin, T. H. (1988). Aristotle's first principles. Oxford: Oxford University Press.

Joachim, H. H. (1904). Aristotle's conception of chemical combination. Journal of Philology, 29, 72-86.

Joachim, H. H. (1970). Aristotle on coming-to-be and passing-away. (De generatione et cormptione). Hildesheim, New York: G. Olims.

Meyer, B. (1932). Harmonia; bedeutungsgeschichte des wortes von homer bis aristoteles. Ph.D. Dissertation, Zurich: Universität Freiburg.

Ross, W. D. (1953). Aristotle's metaphysics, a revised text with introduction and commentary. Oxford: Clarendon Press.

Ross, W. D. (1960). Aristotelis physica. Oxonii: E Typographeo Clarendoniano.

Ross, W. D. (1961). Aristotle: De anima. Oxford: Clarendon Press.

Shields, C. (1988). Soul and body in Aristotle. Oxford Studies in Ancient Philosophy, 6, 103-137.

Sorabji, R. 1975. Body and soul in Aristotle. In J. Barnes, M. Schofield, \& R. Sorabji (Eds.), Articles on Aristotle (pp. 42-64). London: Duckworth.

Todd, R. B. (1996). Themistius: On Aristotle's “on the soul”. Ithaca: Cornell University Press.

Wedin, M. V. (2000). Aristotle's theory of substance: The categories and metaphysics zeta, Oxford Aristotle studies. Oxford: Oxford University Press.

White, N. P. (1971). Aristotle on sameness and oneness. The Philosophical Review, 80, 177-197. doi:10.2307/2184029

Whiting, J. (1992). Living Bodies. In M. C. Nussbaum, \& A. Rorty (Eds.), Essays on Aristotle's De anima. Oxford: Oxford University Press. 